\title{
Design, Experiência e Política: Uma abordagem sobre o papel do Design nos processos democráticos
}

Design, Experience and Politics: An approach about the Design role on the democratic processes

\author{
ELIAN, Matheus T.; Mestre; Universidade do Estado de Minas Gerais \\ mtymburiba@gmail.com \\ RIBEIRO, Rita A. C.; Doutora; Universidade do Estado de Minas Gerais \\ rribeiroed@gmail.com
}

\begin{abstract}
Resumo
Este trabalho procura analisar a construção do Design de Experiência, como ele se aplica no contexto sociocultural atual, e como ele influencia os processos democráticos atuais. Para compreender tais áreas, uma análise dos meios de informação disponíveis e dos seus impactos na sociedade, assim como da fusão dos espaços virtuais e urbanos, e como todos esses elementos contribuem para o direcionamento do viés político individual, foi feita. Considera-se que a influência do mercado nos meios de comunicação pode ser letal para que os processos democráticos sejam livres de manipulações.
\end{abstract}

Palavras Chave: experiência do usuário; design; política.

\begin{abstract}
This paper seeks to analyze the construction of Experience Design, how it is applied in the current sociocultural context, and how it influences the current democratic processes. To understand such areas, an analysis of the available means of information and their impacts on society, as well as the fusion of virtual and urban spaces, and how all these elements contribute to the direction of individual political bias, was made. It is considered that the influence of the market on the media can be lethal so that democratic processes are free from manipulation.
\end{abstract}

Keywords: user experience; design; politics. 


\section{Introdução}

A interpretação dos elementos cognitivos, relativos ao design em relações e experiências, são fatores chave no Design de Experiência. Entender como ocorre a construção da relação humanoobjeto, como as intenções de uma pessoa são influenciadas por uma interação, e como uma interpretação subjetiva de uma interação pode se tornar uma experiência, são aspectos dessa prática projetual que devem ser observados. Historicamente, a literatura e as artes plásticas valorizaram a interpretação e o ato da ideação e significação à luz das crenças individuais. Essa interpretação tem um papel igualmente relevante no Design, e na interação cotidiana com objetos (FORLIZZI, 1997).

A prática do Design de Experiência, em sua essência, pode ser considerada algo que data de séculos atrás. Cerimônias, peças teatrais, e até mesmo a arquitetura (de grandes catedrais medievais, por exemplo) eram projetadas para gerar determinadas experiências. Porém, foi no século XX que o Design de Experiência ganhou mais destaque, devido aos avanços em áreas como a televisão, cinema, rádio, e mais recentemente em mídias eletrônicas como a multimídia, realidade virtual e a Internet (MCLELLAN, 2000).

Os avanços dessas tecnologias, com alta capacidade de processamento de dados, nas últimas décadas geraram a necessidade de se repensar como a informação deveria ser estruturada. Desta forma, acabou-se por ser criada a disciplina de Arquitetura da Informação. Apesar deste termo ser comuns nos dias de hoje, podemos considerar o início de seus estudos foi no ano 1964, com a publicação do artigo Architecture of the IBM System/360 (AMDAHL, et al, 1964), onde seus autores definem "arquitetura" como a estrutura conceitual e o comportamento funcional, que diferem da organização e dos fluxos de dados, do design lógico e da implementação física.

No cenário atual de tecnologias da informação, o smartphone tem um papel crucial. Em uma época que a interatividade e o volume de informações são intensos, tal dispositivo tem uma capacidade de convergência, tanto de meios de comunicação, como de conteúdo, permitindo com que seus usuários se tornem produtores de conteúdo. Diferentemente do que acontece com os meios de comunicação tradicionais, como a televisão e o rádio, a internet permite uma interação direta de seus usuários com o conteúdo e em tempo real. Além disso, a portabilidade dos smartphones, permite com que as pessoas tenham acesso imediato a qualquer tipo de informação disponível, e as redes sociais permitem com que intercomunicação entre usuários seja ainda mais rápida, e com um maior espaço para expressão da individualidade, dado que além de compartilhar informações, os usuários têm a liberdade para expressar sua opinião sobre determinado fato.

O contexto histórico que estamos inseridos é comumente considerado por alguns autores como "Era da Informação", o que permite a reflexão ainda maior sobre o poder da informação. Apesar desse contexto ser atual, o filósofo chinês Sun Tzu já retratava em sua obra, datada de milênios atrás, que o poder da informação pode ser mais efetivo que um exército de maior tamanho. À luz de tal saber, Castells (2009) traz uma abordagem sobre esses efeitos na sociedade: "[...] o poder está baseado no controle da comunicação e da informação, seja ele o poder macro do Estado e das corporações de mídias, seja o poder micro de todos os tipos de organização."

Desta forma, o objetivo deste artigo é apresentar diferentes abordagens do design de informação, como desdobramento do design emocional e de experiência, discutindo suas contribuições para a comunicação, sua relevância e seus impactos na sociedade contemporânea. Para isso, será apresentado diferentes conceituações de emoção, experiência e informação, além 
de abordagens desenvolvidas por pesquisadores do tema.

\section{Análise e discussão}

\subsection{Conceituando Emoção}

Para compreender como a experiência é construída, primeiro é necessário definir os elementos que a constituem, e um dos principais é a emoção. A ideia tradicional de emoção afirma que ela é um processo independente e desprovido de razão. Porém, alguns autores mostram-se contrários a essa ideia, pois ela findou por colocar a emoção como coadjuvante na compreensão da ação humana, e por criar a visão de que tudo que é derivado da emoção é descontrolado, inconsequente e prejudicial (LAZARUS, 1999).

LeDoux (2001) advoga em seus estudos que há uma grande dificuldade de se definir o que realmente é a emoção. Sendo assim, o autor indica que é mais simples indicar o que a emoção não é, do que tentar definir o que realmente ela é. O autor também propõe o conceito de "Circuitos de Sobrevivência" como uma base para compreender processos emocionais comuns aos mamíferos, e nele indica que um sentimento emocional é uma representação de um estado global do organismo iniciado por um estímulo externo. Após o corpo receber um estímulo externo, ele reage através de diferentes capacidades, e atinge um determinado estado global do organismo, que após ser categorizado e rotulado pelo cérebro, tem como resultado um determinado sentimento consciente (como medo, prazer, etc.) (LEDOUX, 2012).

No cenário atual, considera-se que a emoção é um processo tão fundamental para vida quantos os processos racionais, e essa concepção vai além disso. Os processos emocionais e racionais estão em constante interação, que resulta na ideia de que nem toda é emoção é irracional, e que nem toda razão é racional (IIDA et al. 2008).

Martins (2004) advoga que as emoções podem ser entendidas como reações globais do organismo a certos estímulos externos ou internos, que mobilizam o corpo e a mente. Apesar de as emoções não poderem ser diretamente observadas, ou mensuradas, elas podem ser notadas em reações fisiológicas do organismo, como expressões faciais, gestos, ou em demais expressões corporais, como por exemplo, no caso do fight-or-flight - postura de "luta ou fuga" - que é uma resposta aguda ao estresse, gerada pelo organismo em casos de percepção de ameaças (CANNON, 1932). Esta postura em relação a estímulos externos nocivos, são explicadas por alguns autores como o resultado de um processo evolutivo, onde a sobrevivência se sobrepõe a necessidade de compreender um fenômeno (NORMAN, 2008).

\subsection{Conceituando Experiência}

A experiência é conceituada por diferentes autores como o resultado de uma interação com um objeto, ou ambiente, por uma pessoa. Dewey (1980) advoga que a experiência é um fluxo, onde o material experimentado é o caminho da realização. $O$ autor ainda descreve as condições de vida que determinam a natureza de uma experiência comum. Seres vivos existem em um ambiente com o qual interagem constantemente. As condições de vida levadas ao máximo conduziram, fundamentalmente, à comunicação: "A natureza e o homem interagindo entre si, produzem a experiência. O resultado e a recompensa dessa interação do organismo e do ambiente, quando 
levada ao extremo, é a transformação da interação em comunicação." (DEWEY, 1980).

Na visão do autor, a vida pode ser considerada uma sucessão de perda e recuperação de equilíbrio; de desejos e realizações; de fazer e não fazer; as mudanças com o tempo moldam um novo estado de harmonia. Dewey acredita que um organismo desenvolve as condições de ter uma experiência, quando retorna à estabilidade depois de passar por um período disruptivo, pois a partir deste momento ele tem um ponto inicial e final que definem a experiência, que ainda é construída por um ritmo estético, pelas tomadas de ação, pelos sentimentos, e pela significação.

Podemos considerar que Dewey enxerga a experiência e a interação como passatempos ativos. A interação entre o usuário e o objeto ocorre devido a uma expressiva atividade do criador do objeto - no caso, o designer - através do arranjo de materiais para um propósito definido.

O que Dewey chama de experiência é similar ao que Csikszentmihalyi (1981) chama de "transação". A transação, segundo o autor, consiste em duas partes: cultivo, onde ocorre uma ativa formação de significados; e o fluxo, que é a energia resultante da atividade entre o usuário e o produto. Enquanto a experiência segundo Dewey é conceituada como a atividade de interação entre o organismo e o ambiente; a experiência, segundo Csikszentmihalyi, pode ser conceituada como a transação entre o usuário e os elementos que cercam a atividade, como um processo de comunicação onde o objeto é um símbolo que é descoberto, resultando em mais conhecimento e significados para o usuário.

Csikszentmihalyi advoga que apreciação do objeto pelo usuário faz com que o mesmo participe do ato de criação, em um esforço maior do que o do próprio criador do objeto, devido a atribuição de significado. $O$ processo de atribuir o significado é uma comunicação que envolve o objeto e um símbolo. Em adição, o autor define uma pessoa como um ser atento, que tem controle sobre sua existência e que é capaz de dirigi-la em direção a um propósito. As pessoas participariam de atividades, e teriam experiências, porque encontrariam nisso uma forma de fortalecer o seu "eu". A experiência seria uma forma de criação de significados através da ação. Por exemplo, conquistas da vida de uma pessoa são simbolizadas por objetos significativos para ela.

A transação com as coisas existentes é uma parte integral do cultivo de um "eu autêntico". Esse cultivo seria motivado por objetivos pessoais, porém, é limitado pelas capacidades de atenção humana. Esse "eu autêntico" é construído pelo estabelecimento de significados durante a interação com objetos, através da experiência, e baseado em experiências passadas. O cultivo, como processo de interpretação ocorre devido ao fato de outras transações com objetos já terem ocorrido anteriormente, gerando a capacidade de significação pelo indivíduo.

Csikszentmihalyi acredita que os produtos são símbolos devido aos inúmeros significados que eles contêm, num âmbito pessoal, cultural e social, e que são esses significados que podem fazer com que os usuários enxerguem seus valores intangíveis, como o valor de estima, o valor de status que ele pode representar em determinado contexto sociocultural, dentre outros. Por exemplo, um troféu pode ser considerado o símbolo da experiência de vitória, e faz com que seu ganhador sinta felicidade por tê-lo; desta forma, o troféu simboliza felicidade, ou seja, a emoção é comunicada como um resultado da experiência.

\subsection{Design, Experiência, Prazer e Informação}

A experiência resultante da interação com determinado produto faz com que o usuário 
expresse seus julgamentos acerca dela. A hierarquia das necessidades permite com que possamos categorizar os julgamentos de um usuário em diferentes níveis. Green e Jordan (2002) propõem a seguinte hierarquização dessas necessidades em quatro diferentes níveis: o nível 1, quanto a segurança e bem-estar; nível 2, quanto a funcionalidade; nível 3, quanto a usabilidade; e o nível 4, quanto ao prazer.

A categorização do prazer, também chamado de "agradabilidade" por alguns autores, considera o nível emocional das pessoas na interação com objetos. Esse nível de prazer de proporcionado pela experiência com os produtos é chamado de Pleasurability por Jordan (2000) (que em tradução livre, seria a Agradabilidade). Apesar de estar no topo da hierarquia, a percepção de prazer pode estar ligada com os demais níveis. Como apresentado nas definições de experiência por autores como Dewey e Csikszentmihalyi, muitos outros fatores podem ser cruciais para a obtenção do prazer, como o contexto em que o produto está inserido, os aspectos estéticos, e fatores pessoais presentes no ato de significação daquele produto.

É possível entender também que qualquer interação com produtos gere algum tipo de experiência, não necessariamente agradável ou prazerosa. Quando abordamos essa questão pelo ponto de vista do Design, uma experiência ruim, ou desconfortável, pode apresentar claramente um erro de projeto. $O$ design de experiência é focado em buscar soluções sócioculturalmente relevantes no projeto de produtos, serviços, eventos, ambientes, etc. (AARTS \& MARZANO, 2003).

No contexto atual que estamos inseridos, há um número incalculável de informações, produtos e serviços disponíveis, e devido a isso diversos autores pontuam que o Design de Experiência necessariamente tem de prover, além de soluções relevantes, prazer e agradabilidade nas interações. De acordo com Carroll (2004, p.38, tradução do autor):

\begin{abstract}
"Coisas são divertidas quando elas atraem, capturam e prendem nossa atenção através da provocação de percepções novas, ou excêntricas, despertando emoções em contextos que tipicamente não despertam nenhuma, ou não despertando nenhuma emoção em contextos que deveriam despertá-las. Coisas são divertidas quando elas apresentam desafios ou quebra-cabeças a nós, enquanto tentamos criar sentidos e construir interpretações."
\end{abstract}

Brandtzæg et al. (2003) apresenta as três diretrizes para a concepção de tecnologias e experiências agradáveis, sendo elas o controle do usuário e participação, com desafio apropriado; variação e oportunidades múltiplas; e oportunidades sociais, em termos de co-atividade e de coesão social. Esses aspectos observados são essenciais para que projeto de novos produtos crie uma relação mais duradoura com o usuário, influenciando até no prazo de obsolescência dos produtos. A interação com o produto que gera a experiência tem de ser simples, e ao mesmo tempo desafiadora e prazerosa.

Dentro do campo do Design de Experiência temos uma disciplina em destaque, que é o Design de Experiência do Usuário, amplamente conhecida pelo seu termo em inglês User Experience Design, ou UX Design.

Segundo Sharp et. al (2007), a experiência do usuário é resultado da satisfação um indivíduo em relação a um produto. Complementando essa definição, segundo a norma técnica ISO 9241-210: 2009 (ISO, 2009), a experiência do usuário abrange todas as emoções, crenças, preferências, percepções, respostas físicas e psicológicas, comportamentos e realizações dos usuários que ocorrem antes, durante, e depois do uso de sistemas, produtos ou serviços. A análise dessas 
variáveis sob a luz da arquitetura de informação e as metodologias projetuais do Design fez com que tal disciplina fosse criada.

O projeto de experiência do usuário associa todas as características do design de experiência com as práticas metodológicas e projetuais centradas no usuário, pesquisando intensamente o comportamento, a cognição e campo psicológico dos usuários na interação com produtos e sistemas, para que se possa criar soluções de usabilidade que sejam acessíveis, universais, ou que cumpram determinada função. Ou seja, é fazer com que o usuário tenha uma experiência agradável, utilizando um produto da melhor, e mais otimizada, forma possível, maximizando sua interação, e resultando em um aumento dos valores intangíveis percebidos.

Segundo Wurman (1997), o papel da arquitetura de informação é tornar o complexo claro. Tal afirmação também pode ser considerada no design de experiência de usuário, pois a estruturação da informação, assim como a análise de comportamento, cultura, conteúdo e necessidades, permite a otimização de interfaces, e consequentemente uma experiência mais simples e prazerosa ao usuário, e ao mesmo tempo permite uma maior rapidez nas ações e uso das soluções.

O trabalho dos UX designers exige um intenso número de testes de usabilidade, para que se tenha dados suficientes para entender o comportamento daquele usuário e direcioná-lo para o uso que se deseja projetar. Quando se trata de aplicativos para smartphones e páginas de websites, essas métricas são facilmente percebidas, e esses dados podem significar grandes impactos para as empresas desenvolvedoras de tais produtos. Um dos exemplos mais clássicos de como o design de experiência pode impactar diretamente uma empresa é no caso conhecido como "41 tons de azul", do Google, onde o time responsável por determinar o visual da página de buscas da empresa não conseguia se decidir entre dois tons de azul para serem usados nos links dos resultados da pesquisa. Desta forma, resolveram testar 41 tons, que estavam entre os dois tons de azul originalmente discutidos, assim como pequenas variações nas fontes do corpo de texto da página. De acordo com dados obtidos, o time responsável conseguiu identificar qual tom de azul que mais atraía os usuários a clicarem, e esta mudança da cor fez com que a empresa lucrasse mais de 200 milhões de dólares em venda de anúncios (HERN, 2014).

Ainda quando abordamos os smartphones no contexto social atual, percebemos que o design de experiência aplicado nessa plataforma contribui cada vez mais para que ele atue como um centro de convergência de diversos fatores. Esta convergência pode ser compreendida de acordo com o que Jenkins (2008) advoga:

\footnotetext{
"Por convergência refiro-me ao fluxo de conteúdos através de múltiplas plataformas de mídia, à cooperação entre múltiplos mercados midiáticos e ao comportamento migratório dos públicos dos meios de comunicação, que vão a quase qualquer parte em busca das experiências de entretenimento que desejam. Convergência é uma palavra que consegue definir transformações tecnológicas, mercadológicas e sociais [...] uma mudança no modo como encaramos nossas relações com as mídias. Estamos realizando essa mudança primeiro por meio de nossas relações com a cultura popular, mas as habilidades que adquirimos nessa brincadeira tem implicações no modo como aprendemos, trabalhamos, participamos do processo político e nos conectamos com pessoas de outras partes do mundo."
}

Essa mudança citada por Jenkins já pode ser notada no processo político atual. Tal convergência de conteúdo e informações nas redes sociais, assim como a capacidade de interação destas, influenciou diretamente a eleição americana de 2016, por exemplo (SEETHARAMAN, 2016). 


\subsection{A influência do Design na política}

As redes sociais estão presentes em um gigantesco número de pessoas ao redor do mundo. O Facebook possui mais de 1,84 bilhão de usuários ativos, sendo que destes, 1,15 bilhão estão ativos diariamente (FACEBOOK, 2017). Um dos pontos que justifica tamanha adesão às redes sociais, seria o fato dela permitir a expressão de individualidade em um contexto onde não há uma verticalização de hierarquia, permitindo assim uma autonomia. Segundo Castells (2009), "A chave para o processo de individuação é a construção da autonomia pelos atores sociais, que se tornam sujeitos no processo.".

Esse processo supracitado constitui parte da experiência projetada para tal plataforma. É necessário compreender que acima de uma plataforma de interação social, as redes sociais são produtos, e desta forma, as empresas que as criaram visam lucros. Estes lucros vêm, normalmente, da venda de espaço publicitário no feed de notícias de seus usuários. Para aumentar este lucro, as empresas utilizam de algoritmos capazes de interpretar a experiência do usuário no uso da rede social, entendendo quais são seus interesses, suas opiniões e gostos pessoais. As métricas geradas pelo uso retroalimentam o sistema, que é capaz de distinguir qual conteúdo é mais pertinente a ser exibido àquele usuário, melhorando a sua experiência na interação com a informação. Para compreender quão grande é este mercado, com as vendas de anúncios, o Facebook lucrou mais de 8 bilhões de dólares somente no primeiro bimestre de 2017 (FACEBOOK, 2017).

É necessário entender que, na sociedade atual, as redes sociais não estão isoladas no meio virtual, elas estão presentes diariamente na vida das pessoas, gerando o que Castells (2009) chama de "espaço da autonomia", que é um híbrido do virtual com o urbano. Ainda sobre as redes sociais, Castells (2009) também afirma: "[...] são sociedades autoconstruídas pela rede e em conexão a outras redes. Entretanto, não são sociedades virtuais: há uma estreita ligação entre redes virtuais e redes na vida em geral. Trata-se de um mundo híbrido, um mundo real; não um mundo virtual ou um mundo segregado.".

A expressão da individualidade nesse espaço de autonomia contribui para o processo político. Nesse âmbito o Design de Experiência pode influenciar na forma com que os usuários interpretam as informações, e consequentemente, como formam sua opinião. Isto ratifica ainda o que Castells advoga sobre a cognição política, cuja indica ser formada emocionalmente. A tomada de decisão pode ser racional, avaliando novas informações; ou emocional, através dos mapas cerebrais. Percebe-se então que as emoções relevantes para a cognição política são o entusiasmo, a ansiedade e o medo. Essas emoções influenciam diretamente na postura dos cidadãos em relação à política, dado que podem denotar uma aversão aos riscos, cautela, ou o inverso dessas atitudes (CASTELLS, 2009).

Quando abordamos essa cognição nas redes sociais, é sabido que ela também pode sofrer influências dos algoritmos que gerenciam a exibição de conteúdo individual. Como estes utilizam os dados obtidos através da utilização individual, o próprio usuário pode findar por receber apenas informações que já correspondem a sua própria ideologia já estabelecida. Alguns autores chamam esta situação de "bolha ideológica", ou "bolha virtual", já Popkin (1994), chama as pessoas que procuram apenas informações que confirmem suas crenças e hábitos de seu viés ideológico existente, de "avarentos cognitivos". Apesar do termo negativo, podemos analisar até que ponto é 
prejudicial esta situação para o usuário, dado que Castells (2009) indica que toda política é pessoal. O que pode ser notado no seguinte trecho de sua obra: "Não há a "política geral"; é sempre a "minha política" processada pelos padrões neurais do meu cérebro e posta em prática por meio das decisões que articulam minhas emoções e minhas capacidades cognitivas, comunicadas pelos meus sentimentos.".

A "minha política", citada pelo autor, é fruto de experiências, emoções e sentimentos individuais. Porém o que podemos encontrar nas redes sociais é que a "minha política" não é resultante apenas desses fatores. Soma-se a estes o resultado da experiência do usuário determinado pelo algoritmo que estrutura a informação e conteúdo de cada uma das redes. Apesar da cognição política individual ser formada por diferentes contribuições mesmo antes do advento da internet, e ser passível de influência, o que temos hoje é substancialmente mais subliminar.

No cenário atual, onde a mineração de dados é mais facilmente executada, empresas foram criadas justamente para interpretar esses dados. Estas empresas criaram um método que alguns autores chamam de Psicometria, para traçar em detalhes os perfis de usuários nas redes sociais, baseados em seus likes, e assim direcionar o marketing político da forma mais efetiva possível para um determinado público. Um dos principais pesquisadores atuantes neste ramo do mercado, é o Michal Kosinski, um especialista desse modelo de análise psicométrico. Sobre a construção de tal modelo por Kosinski, Krogerus e Grassegger (2017) relatam:

\footnotetext{
"Kosinski e sua equipe refinaram incansavelmente seus modelos. Em 2012, Kosinski provou que, com base numa média de 68 "curtidas" no Facebook, era possível descobrir a cor da pele de um usuário (com $95 \%$ de probabilidade de acerto), sua orientação sexual (88\%) e sua filiação no partido Democrata ou Republicano (85\%). Mas não parou por aí. Inteligência, filiação religiosa, assim como uso de álcool, fumo ou droga podiam todos ser determinados. A partir dos dados era possível deduzir se os pais de alguém eram divorciados."
}

Desta forma, podemos perceber que se há um interesse dos setores privados, financiados pelos próprios atores do meio político, que influencia diretamente na experiência dos usuários das redes sociais, pode-se compreender que a cognição política das pessoas pode acabar se tornando, de forma definitiva, um produto. Como grande parte da população mundial não é ciente desse tipo de atividade, acabam sendo mais suscetíveis a este tipo de influência. Este fato, por fim, corrobora a afirmação de Castells (2009): "Minha hipótese de trabalho é que a forma mais fundamental de poder está na capacidade de moldar a mente humana.".

\section{Considerações Finais}

Ao analisar o papel da emoção e da experiência no design no contexto contemporâneo, percebemos que progressivamente, as tecnologias projetadas trazem consigo uma forte capacidade de interação social, e de horizontalidade na comunicação, permitindo uma maior inserção das pessoas no processos sociais e políticos atuais. Porém, como a posse de informações é algo extremamente valioso, as redes sociais, por exemplo, acabam por ser ferramentas de influência de marcas, companhias e políticos, dado que a obtenção de dados neste ambiente é muito simples de ser arquitetada.

Casos recentes, como o caso da empresa Cambridge Analytica, que utilizou dados de milhões de usuários do Facebook, criando perfis "piscográficos" de cada usuário para direcionamento de tipos específicos de propagandas políticas, demonstra como a usabilidade e a experiência de certos 
produtos digitais tem sido projetadas para influenciar seus usuários de acordo com interesses de determinadas pessoas ou corporações. Ao mesmo tempo que se tem uma maior liberdade na comunicação, a forma em que as informações são estruturadas e disponibilizadas pelos algoritmos faz com que a horizontalidade da comunicação seja comprometida, o que pode ser constatado depois do caso da Cambridge Analytica, dado que essa exploração de dados e informações pode ter influenciado diretamente a eleição americana no ano de 2016 (AL JAZEERA, 2018).

A aproximação que este artigo traz sobre as obras dos autores citados, principalmente Manuel Castells, ajuda a compreender como a interação entre os espaços virtuais e urbanos, acaba por transformar o contexto social em que vivemos, e como todo esse volume de informações que recebemos pode acabar por deturpar certas áreas do entendimento e da cognição sociopolítica, e os processos democráticos em si.

Ao percebermos como nossas experiências, principalmente no espaço virtual, são projetadas não só para a otimização de nossas ações, mas também para influenciar nosso perfil ideológico, podemos crer que a atuação do Design pode ser decisiva para que certas ideias se sobressaiam às outras. Essa possível corrupção na criação de soluções, no momento, começa a transcender da questão do lucro em si, para algo que condensa muito mais o poder na mão dos detentores do capital financeiro e político, contaminando claramente os processos democráticos, e reforçando uma lógica perversa trazida pelo capitalismo, por todo o mundo.

\section{Referências}

AARTS, E. H. L.; MARZANO, S. The New Everyday: Views on Ambient Intelligence. 010 Publishers, 2003.

AL JAZEERA. Cambridge Analytica and Facebook: The scandal so far. Al Jazeera News: Privacy \& Surveillance, 2018. Disponível em: <https://www.aljazeera.com/news/2018/03/cambridgeanalytica-facebook-scandal-180327172353667.html>. Acesso em 02/04/2018.

BRANDTZEEG, P. B.; ASBJ ØRN, F.; HEIM, J. Enjoyment: lessons from Karasek - Introduction to Funology, Springer Netherlands, 2005, p. 55-65.

CANNON, W. Wisdom of the Body. W.W. Norton \& Company, 1932.

CARROLL, J. M. Beyond Fun. Interactions, 2004, p. 38-40.

CASTELLS, M. Communication Power. Nova lorque: Oxford, 2009.

CSIKSZENTMIHALYI, M.; ROCHBERG-HALTON, M. The Meaning of Things. Boston: Cambridge University Press, 1981.

DEWEY, J. Art of Experience. New York: Perigree Books, 1980.

FACEBOOK. Facebook Q1 2017 Results. Facebook, 2017.

FORLIZZI, J. L. Design for Experience: An Approach to Human-Centered I. Carnergie Mellon University, 1997.

GREEN, W. S.; JORDAN, P. W. Pleasure with products: Beyond usability. London: Taylor \& Francis, 2002.

HERN, A. Why Google has 200m reasons to put engineers over designers. The Guardian, 2014. 
Disponível em: <https://www.theguardian.com/technology/2014/feb/05/why-google-engineersdesigners> Acesso em 12/07/2017.

IIDA, I.; BARROS, T.; SARMET, M. A Conexão Emocional no Design. Caderno de Estudos Avançados em Design: Transversalidade, caderno 2, 2008.

ISO. ISO: 9241-210:2009 - Ergonomia da interação sistema humano. International Organization for Standarlization, parte 210, 2009.

JENKINS, H. Cultura da convergência. São Paulo: Aleph, 2008

JORDAN, P. W. Designing pleasurable products. London: Taylor \& Francis, 2000.

KROGERUS, M.; GRASSEGGER, H. Big Data: Toda Democracia será manipulada? Outras Palavras, 2017. Disponível em: <http://outraspalavras.net/posts/big-data-toda-democracia-seramanipulada/> Acesso em 13/07/2017.

LAHEY, T. J. Modelling Hysteresis in the Bending of Fabrics. University of Waterloo, 2002.

LAZARUS, R. S. The cognition-emotion debate: a bit of history. New York: John Wiley \& Sons, 1999.

LEDOUX, J., O Cérebro emocional. Os misteriosos alicerces da vida emocional. Rio de Janeiro: Objetiva, 2001.

LEDOUX, J., Rethinking the Emotional Brain. Neuron 73, Elsevier, 2012.

MARTINS, J. M. A Lógica das emoções na ciência e na vida. Petrópolis: Vozes, 2004.

MCLELLAN, H. Experience Design. CyberPsychology \& Behavior. Vol. 3. Mary Ann Liebert, Inc. 2000. NORMAN, D. A. Emotional design. New York: Basic Books, 2004.

PINE, B.J., III; GILMORE, J.H. The experience economy: Work is theater and every business a stage. Cambridge, MA: Harvard Business School, 1999.

POPKIN, S. L.; The Reasoning Voter: Communication and Persuasion in Presidential Campaigns. Chicago: University of Chicago Press, 1994.

SEETHARAMAN, D. Redes sociais influenciam eleitores dos EUA em 2016. The Wall Street Journal, 2016. Disponível em: < https://www.wsj.com/articles/redes-sociais-influenciam-eleitores-dos-euaem-2016-1478840879> Acesso em 12/07/2017.

SHARP, H.; ROGERS, Y.; PREECE, J. Interaction Design: Beyond Human-Computer Interaction. 2nd Edition, New York: John Wiley \& Sons, Inc, p.70, 2007 